\title{
ANALYSIS \\ The battle of perspectives: a multi-agent model with adaptive responses to climate change
}

\author{
Marco Janssen *, Bert de Vries \\ Bureau for Environmental Assessment (MNV), National Institute of Public Health and the Environment (RIVM), P.O. Box 1, 3720, \\ Bilthoven, The Netherlands
}

Received 7 July 1996; received in revised form 14 April 1997; accepted 21 April 1997

\begin{abstract}
To evaluate possible futures with regard to economy, energy and climate, a multi-agent modelling approach is used. Agents hold different perspectives on how the world functions (worldview) and how it should be managed (management style) and this is implemented in a simple dynamic model of the economy-energy-climate system. Each perspective is supported by a proportion of the agents, but this proportion changes in response to observations about the real world. In this way the totality of agents learn from their observations. It is concluded that this approach is a good illustration of how adaptive behavior can be included in global change modelling. Some exploratory experiments are done to address the consequences of surprises. (C) 1998 Elsevier Science B.V. All rights reserved.
\end{abstract}

Keywords: Global change; Integrated assessment modelling; Perspectives; Multi-agent modelling

\section{Introduction}

In this paper, we present an approach which includes explicitly the adaptive behavior of humans in the face of incorrect assumptions about

\footnotetext{
* Corresponding author. Tel.: + 3130 2742432; fax: + 31 30 2744435; e-mail: Marco.Janssen@rivm.nl
}

the functioning of the global system. We focus on the problem of human-induced climate change, since several aspects of this problem are controversial and it has an important policy component. Although the majority of climate researchers support the theory of the enhanced greenhouse effect (IPCC, 1990, 1996a,b,c), it is unclear where and how fast temperature increases will occur and what the impact will be on the biosphere, including human society. 
Not surprisingly, many attempts to understand and forecast the future development of such complex systems have failed. For instance, Malthus (1798) regarded food production as a land-limited resource that could not possibly be increased quickly enough to keep in pace with a growing population. His expectation did not come true for various reasons, among them the sharp increase in agricultural productivity and the decrease in birth rates. Another example is provided by the 1971 report to the Club of Rome, Limits to Growth (Meadows et al., 1972), which concluded from a model-based analysis that the ongoing depletion of resources would result in a collapse of the world economy. However, the oil crisis of the 1970s led to intensification of exploration efforts and subsequently additional reserves; they also induced investments in energy efficiency and renewable energy sources (Meadows et al., 1991). The simulations made in 1971 did not include either the oil crisis nor the responses to it. The complexity of the system is seriously underestimated in such analyses. This is particularly true with respect to the response and adaptation options and the capability of humans to apply and expand such options.

One of the tools to deal with the complex interactions between the economy and the climate system is an integrated assessment model. These models link simplified versions of expert models into an integrated model which is used to support policy making. Two of the techniques used are scenario analysis and optimization. Scenario analyses tend to lose their meaning if scenarios are reduced to simple trend extrapolation without any human response, as is often the case. Optimization is based on the assumption that rationally acting agents have perfect knowledge about the system in question and are able to determine the optimal strategy for some future period. Although this approach may yield valuable insights into efficient strategies, it is seriously limited by the necessary model simplifications. Thus, there is a need to support scenario analyses with modelbased simulation experiments without resorting to abstract, oversimplified system descriptions. Inclusion of adaptive agent behavior can contribute to this.
The recognition that changing behavior of agents should be an important consideration in global modelling is not new (Bossel and Strobel, 1978). During recent years, a number of studies related to climate change have appeared which investigate the concept of adaptive or sequential decision-making (Manne and Richels, 1992; Hammitt et al., 1992; Peck and Teisberg, 1992; Lempert et al., 1995). The first three of these studies employ a sequential-decision model in which the optimal trajectory is derived in two steps, taking account of a learning phase in the initial period. In Lempert et al. (1995), a simple adaptive strategy is examined, whereby different assumptions of the costs and damage functions are juxtaposed with optimal policies. Another approach to modelling social behavior is the 'artificial society'. An interesting example is to be found in the work of Epstein and Axtell (1996), who designed a program which generates artificial societies by modelling simple rules for hundreds of individual agents which evolve over time. The purpose of such an artificial society is to enable the investigation of social processes within a so-called 'CompuTerrarium'.

These models do not take into account the diversity of worldviews among the agents. Thompson et al. (1990) argue that agents are forced to cast around for alternatives in the event that they are confronted with a persistent pattern of surprises, and that this constitutes an important element of social dynamics. So far, only a few studies have tried to model such changing worldviews or perspectives. Thompson and Taylor (1986) devised a computer simulation of a 'surprise game' in which a so-called payoff matrix is used to value the 'nice' and 'nasty' consequences of various surprises. The game was implemented for an imaginary industrial enterprise with a considerable number of competitors, and simulates the number of adherents to one of the four perspectives distinguished in the Cultural Theory: Egalitarians, Hierarchists, Individualists, and Fatalists.

In a set of exploratory experiments, Janssen and Rotmans (1995) generated various scenarios in which climate policy changes as a result of shifts in the dominant perspective among the 
agents. The dominant perspective may change if expectations about the functioning of the system fail to correspond with reality. The study assumed that scenarios would involve change of perspectives, but did not simulate the underlying dynamics of how agents may change their perspectives. The aim of this paper is about this 'Battle of Perspectives'.

\section{Perspectives and agents}

The first element of our approach is a simple economy-energy-climate model which through different relationships and parameter values is used to describe three different views on how the world functions and on how it should be managed. The model is described in the next paragraph. The second element is the inclusion of explicit perspectives on the world system and of agents which base their decisions on such perspectives in relation to real-world observations.

As a framework to classify possible diverging interpretations of the world, the three 'active' perspectives from Cultural Theory are used: the Hierarchist $(\mathrm{H})$, the Egalitarian $(\mathrm{E})$ and the Individualist (I) (Thompson et al., 1990; Rayner, 1991; Thompson, 1996). The perspectives are interpreted as the corners of a triangle and the agent population can at any moment in time be positioned within this triangle if it is known which proportion adheres to each of the three perspectives. Briefly, the three perspectives can be characterized as follows for the energy climate debate (De Vries and Janssen, 1996).

The Hierarchist wishes to avoid disruptions to the smooth functioning of the energy system in view of its consequences for economic growth and voter behavior. To this end the Hierarchist institutions of society will anticipate and respond on the basis of scientific expert knowledge. The need for governance structures is emphasized. There is a preference for a risk-reducing control approach and for reliance on and legitimization by the outcomes of cost minimization and cost-benefit analyses. Technologies which can be planned and controlled are favored and issues like oil dependence and public acceptance rank high. Energy consumers can and should be guided towards 'rational energy use' - which is the justification for regulation, taxes, information campaigns and the like.

The Hierarchist will make a prudent assessment of the potential for energy conservation and have an institutional bias towards large-scale supplyside options. Resource estimates will be rather conservative. There will be a cautious approach in the issue of climate change, judging it in terms of 'acceptable risks', including strategic and societal risks such as the OPEC-oil oligopoly, nationalism and fundamentalism. Hierarchists will support cost-effective 'no-regrets' measures which reduce the risk of climate change, but they are keenly aware of the fact that fast and stringent cutbacks in $\mathrm{CO}_{2}$ emissions may be socially disruptive and create competitive disadvantages. Hence, a climate policy should be 'realistic' and only be introduced if an internationally negotiated consensus is reached to avoid windfall profits or free riders (Hourcade et al., 1995). Hierarchists prefer unambiguous, scientifically robust indicators on which to found their analyses and policies, e.g. global mean temperature change. $\mathrm{R}$ and $\mathrm{D}$ programs for new energy supply and efficiency options are advocated, also because they stimulate economic growth and (national) status.

The Egalitarian wishes to reduce inequity and stresses the rights of those without a voice: our children, the poor and nature. High and rising $\mathrm{CO}_{2}$ emissions are seen as one more sign that humans are maltreating the earth and that this may lead to catastrophes. The aspiration for continuing economic growth has to be curbed, which is only fair and feasible if it is accompanied by a narrowing of the gap between the rich and the poor. Mathematical tools and models can play only a minor role because many of the issues at stake cannot be expressed in numbers or money. From an Egalitarian perspective, science and technology can certainly solve part of the problem, but add as much to it as long as their course is governed by centralized and commercial interests and market ideology. Being risk-aversive, Egalitarians consider all uncertain processes and feedbacks to have amplified climate change. They also wish to consider feedbacks or catastrophic im- 
pacts into account, which are strongly disputed within the scientific community; on the other hand, they tend to ignore potential negative feedbacks.

The Egalitarian will embrace the 'precautionary principle' as a way to express his/her risk-averse attitude. Energy futures will be judged not only in terms of costs, but also with regard to distributive aspects and ecological impacts. Hence, policies should be based on assessment studies of the possible impacts from anticipated increases in temperature and sea level. No growth or only a modest economic growth is to be preferred. Energy taxes are promoted as means to change wasteful production and consumption practices and stimulate the penetration of non-polluting alternatives. It will also conserve high-quality oil and gas reserves for later generations. Energy demand projections are much lower than official ones and have to be met to a large extent with non-fossil sources (Lovins and Lovins, 1991). There will be a preference for decentralized and clean technologies, and therefore a natural tendency to focus on energy end-use needs and efficiency (Johansson et al., 1989). Estimates of fossil fuel resources are on the low side, whereas the prospects of renewable energy sources are usually on the high side if compared with the Hierarchist perspective. Development of renewable sources should be strongly supported by government $\mathrm{R}$ and D programs.

For the Individualist, entrepreneurial freedom and unhampered working of market forces gives the best guarantee for increasing material wealth and at the same time solving resource and environment problems. If energy supply companies can operate in a regime of free trade and with a minimum of government regulation and interference, price signals will steer the transition away from fossil fuels before they are depleted. The earth itself is also far more resilient than we tend to think, so climate change impacts are probably exaggerated by those advocating strict measures. Moreover, there are several and relatively cheap options for adaptation (Nordhaus, 1991). The key resource is human ingenuity: human skills generate science and technology, which will bring options one cannot even imagine at the present
(Simon, 1980). Technology is also the major driving force behind economic growth, which will ultimately benefit the poor. Concerning the climate change debate, the Individualists' view of a benign natural system leads them to believe that climate change will be mitigated by known and hitherto unknown dampening feedbacks. Speculative negative feedbacks are taken into account; uncertain positive feedbacks are neglected or considered to have negligible impacts on the climate system.

The Individualist emphasizes the opportunities which arise from the search for new resources and new technologies to supply and conserve energy. Energy resources turn out, over and again, to be more abundant and cheaper than expected. Policy measures like a carbon tax are unnecessary and may actually be quite harmful to the legitimate aspiration of the less developed countries to spur economic growth. Moreover, there are still too many uncertainties about the enhanced 'greenhouse' effect and possible climate change to accept drastic measures. Energy taxes will also be ineffective because industries will move to other countries and consumers will stick to certain lifestyles whatever the costs.

Of course, in the real world, actors rarely express their views in such a caricatural way. They are in constant interaction and often have strategic and public relations in mind as well. Moreover, positions may be implausible or even inconsistent when stake holders share only part of the underlying values and judgments. For example, the Egalitarian concerns about nuclear reactor safety and climate change have increasingly been incorporated in Hierarchist policy formulation in the form of regulatory and negotiation frameworks. Similarly, the energy business community - part of which is rather Hierarchist - is advocating the need for more efficient and environmentally friendly resource use options, at the same time emphasizing the virtues of the market and the limitations of command-and-control approaches (Schmidheiney et al., 1992). There is also the paradox that the Egalitarian expectation of fast innovation in energy efficiency and non-carbon energy supply and imminent depletion of cheap oil and gas is at odds with their fear that 
the high $\mathrm{CO}_{2}$ emissions of the 'business-as-usual' scenarios become reality (Lenssen and Flavin, 1996). Evidently, our implementation of the three perspectives, into an economy-energy-climate model is only a first attempt to introduce realworld divergence in interests and values into a quantitative modelling framework.

Trisoglio et al. (1994) have proposed to characterize perspectives according to two dimensions: (1) how is the world seen - the worldview; and (2) how it should be acted upon - the management style. A management style is correct in so far as it is based on a corresponding view on how the world functions. For example, if one believes that people will change their behavior only in response to prices, market-oriented policies are most effective and to be preferred. Trisoglio et al. (1994) refer to this situation as utopian: the management style of agents corresponds with their view of the world. If, on the other hand, a management style is followed which is not based on correct understanding of the system, the situation is dystopian. The literature on utopias has a long history (More, 1516; Kumar, 1987; Proops, 1989). The previously mentioned doomsday scenarios of Malthus and Meadows et al. can be seen as dystopias: human behavior and (lack of) policies are discordant with nature's resource potential and resilience. [Meadows et al. $(1972,1991)$ also present scenarios which avoid catastrophe by combinations of policies - these can be interpreted as utopias. Bossel and Strobel (1978) simulate utopias by inclusion of explicit adaptive behaviour.] A rather dystopian scenario for climate change is the 'business-as-usual' or IS92a scenario of the IPCC (1992). This coal-based energy future with medium population and economic growth leads to a greenhouse gas emission path which probably implies serious climate change related risks. Indeed, this scenario is used as a reference future to formulate emission targets.

The utopia/dystopia approach can be used to explore a variety of images of the world's future (Van Asselt and Rotmans, 1996; Rotmans and de Vries, 1997). However, in these applications it is static in the sense that an evolving dystopia does not induce adaptive behavior. If the system col- lapses, the agents do not respond. Hence, the scenario outcomes are rather implausible, although they give insight in the role of uncertainties. The present approach is an important improvement in this regard, because the agents in the model are assumed to change their preferred management style if observations about the world are surprising enough, that is, if they differ enough from what they expect on the basis of their worldview. Of course, we realize that this model is for illustrative purposes only and that only implementation in more detailed simulation models can support issues in climate policy.

We populate the model-world with a large number of agents which adhere to a mix of the three perspectives, but may change their adherence and change policy if their observations do not match their expectations. These agents can be thought of as groups of decisionmakers who operate at the international level and represent institutions. [A far reaching simplification in this paper is the ignorance of the many decisions of consumers on the microlevel, and the assumption that institutional actors may control behavior at the microlevel.] In this way, the system's behavior does not deterministically follow from a set of state equations, but is instead governed by the rule-based behavior of many distributed, interacting parts. These rules influence the actions of an agent which in turn affects the actions of other agents. The resulting rule-based structure becomes grist for the evolutionary procedure that enables the system to adapt to its surroundings.

The method employed in this paper is called genetic algorithm. Holland (1975) has tried to abstract and explain the adaptive processes of natural systems and developed a mathematical representation of the processes: the genetic algorithm. The basic construction is to consider a population of individuals in which each individual represents a potential solution to a problem - in our example, the climate change problem. The relative success of each individual in solving the problem is considered to be an indicator of that individual's fitness. By virtue of natural selection, the most fit individuals produce similar, albeit non-identical, offspring for the next generation. Next, genetic operations like cross-over and muta- 
tion make the offspring different from their parents. This concept of the survival of the fittest, as simulated by the genetic algorithm, is a strong tool to simulate optimizing behavior (Goldberg, 1989), and is, therefore, applied to model biological and social agents (Holland and Miller, 1991; Holland, 1992; Waldrop, 1992; Janssen, 1996).

\section{The economy-energy-climate model}

For the purpose of this study, a simple dynamic system is employed which describes the basic dynamics of the economy and the climate system. The model is based on existing economy-climate models, such as those found in: Nordhaus (1994), Manne et al. (1994), Hammitt et al. (1992), Lempert et al. (1995). Here we only give the key equations; a more detailed description can be found in Janssen (1996). We recognize that this model yields a highly simplified representation of the problem, but its dynamic framework serves well to illustrate the 'Battle of Perspectives'.

There are three parts to the model: economy, energy/emissions and climate. The description of the economy is based on a single equation for aggregate economic output:

$$
Y(t)=c S(t) \cdot a(t) \cdot K(t)^{\gamma} \cdot P(t)^{1-\gamma} \quad \$ / \mathrm{yr}
$$

This is a standard constant-returns-to-scale, Cobb-Douglas production function with two production factors: capital $K(t)$ and labor $L(t)$ which is assumed to be proportional to population, $P(t)$. It also contains technical progress in the form of an exogenous factor $a(t)$. To account for the economic consequences of either climate change related damage or emission reduction measures, the scale factor $S(t)$ is introduced. Both $a(t)$ and $S(t)$ are normalized to 1 for the base year 1995 . For the world population we use an exogenous projection of 11.3 billion people in 2100 , published in Bulatao et al. (1990). Technological change is assumed to increase exponentially, but at a declining rate, following Nordhaus (1994). Gauging the equation to the world data for 1990, US\$ yields for the constant $c$ in Eq. (1) the value of 0.0132 . The elasticity of output with respect to capital, $\gamma$, is taken to be 0.25 . The scale factor $S(t)$ is discussed later on.
Economic output is produced by an aggregate capital stock, $K(t)$, which has an average lifetime of 10 years. In combination with a savings rate $I(t)$, i.e. the fraction of economic output $Y(t)$ re-invested in the capital stock $K(t)$ in period $t$, the balance equation for the capital stock $K(t)$ is given by:

$$
\frac{\mathrm{d} K}{\mathrm{~d} t}=I \cdot Y-\delta_{\mathrm{k}} \cdot K \quad \$ / \mathrm{yr}
$$

with $\delta_{\mathrm{k}}$ the rate of depreciation of the capital stock and equal to the inverse of the average lifetime. Total consumption, $C$, is equal to economic output, $Y$, minus gross investments, $I Y$ :

$C(t)=(1-I(t)) \cdot Y(t) \quad \$ / \mathrm{yr}$

The second part of the model describes the energy system. It is kept quite simple. The economy uses energy at an intensity $\varepsilon$, i.e. the amount of fuel required per unit of economic output. This energy-intensity $\varepsilon$ is assumed to decline logistically to some lower bound $\varepsilon_{\text {min }}$. The rate at which energy efficiency improvements are introduced and hence the rate at which $\varepsilon$ declines is given by the parameter $L_{\mathrm{e}}$ which indicates the number of years it takes to halve the initial (1995) value of $\varepsilon$. We call this phenomenon the energy efficiency transition. The pace of the energy efficiency transition is given with $L_{\mathrm{e}}$ which ranges from 40 to 60 years.

The energy is supplied to the economy as a mix of fuels of which a fraction $F(t)$ consists of fossil fuels. These give on combustion a fixed amount of $\mathrm{CO}_{2}$ emissions per unit of energy. Here, too, we assume a transition away from fossil fuels in the form of a logistic decline of $F(t)$. The rate of change is determined by the parameter $L_{\mathrm{f}}$ which indicates the number of years it takes to reduce the initial (1995) value of $F(t)$ with $50 \%$. We refer to this as the fossil fuel transition. In our simulation experiments, the value of $L_{\mathrm{f}}$ ranges from 20 to 1000 and is used as a control variable.Using these formulations, the emission of $\mathrm{CO}_{2}$ is given by:

$E(t)=\alpha F(t) \cdot \varepsilon(t) \cdot Y(t) \quad \mathrm{GtC} / \mathrm{yr}$

The $\mathrm{CO}_{2}$ emissions $\mathrm{E}$ are the result of a change in economic activity $Y(t)$, the energy conservation 
transition in the form of a declining energy-intensity $\varepsilon(t)$ and the transition towards alternative fuels in the form of a declining value of $F(t)$. Equating $Y(t)$ to the gross world output (GWP) expressed in 1990 US\$, the coefficient $\alpha$ Eq. (4) gets the value of $0.32 \mathrm{GtC} /$ billion $\$$.

The third part of the model consists of a greatly simplified climate model. The change in atmospheric $\mathrm{CO}_{2}$ concentration $\left(\mathrm{pCO}_{2}\right.$ in $\left.\mathrm{ppmv}\right)$ is modelled using the reduced-form carbon cycle model developed by Maier-Reimer and Hasselmann (1987). The radiative forcing of $\mathrm{CO}_{2}$ is modelled in conformity with the IPCC (1990) such that we derive the following impact on the change in the global mean surface temperature:

$$
\Delta T^{p}(t)=\frac{\Delta T_{2} \times \mathrm{CO}_{2}}{\ln (2.0)} \cdot \ln \left(p \mathrm{CO}_{2}(t) / p \mathrm{CO}_{2}\left(t_{0}\right)\right) \quad{ }^{\circ} \mathrm{C}
$$

where $\Delta T_{2 \mathrm{xCO} 2}$ is the global mean surface temperature change in the event of a doubled $\mathrm{CO}_{2}$ concentration (best guess $2.5^{\circ} \mathrm{C}$, see Section 4.2). Since oceans take a long time to warm up, the actual temperature increase $(\Delta T)$ will lag behind the potential increase, $\Delta T^{\mathrm{p}}$, which is modelled as follows:

$\frac{\mathrm{d} \Delta T}{\mathrm{~d} t}=\beta \cdot\left(\Delta T^{p}-\Delta T\right)$

where $\beta$ is assumed to be 0.05 . This causes a delay time in the order of 20 years.

It is assumed that a rise in the average surface temperature brings costs in the form of damage and/or adaptation measures. These are accounted for in the form of economic output reduction. On the other hand, these costs can be avoided or lowered by preventive measures in the form of emission reduction measures. In our model, this is done by accelerating the transition away from fossil fuels and it has a cost, too.

The scaling factor $S(t)$ in the expression for the economic output $Y(t)$ (Eq. (1)) takes these two factors into account. The (market) damage and/or adaptation costs are quantified as a relation between global temperature $\Delta T(t)$ increase and income loss. The costs of reducing emissions of greenhouse gases are assumed to be a function of $F$, the fraction of fossil fuels in the energy mix.
Now, $S(t)$ is defined as the ratio of one minus the percentage of abatement costs to one plus the percentage of damage costs:

$S(t)=\frac{1-b_{1} \cdot(1-F(t))^{b_{2}}}{1+\theta_{1} \cdot \Delta T(t)^{\theta_{2}}}$

with $\theta_{1}$ representing the scale of damage and/or adaptation, $\theta_{2}$ the non-linearity in the damage function, and $b_{1}$ and $b_{2}$ the scale and non-linearity of the emission reduction cost function.

\section{Modelling worldviews and management styles}

\subsection{Experimental set-up}

The agents are assumed to represent decisionmakers on an international level, who are responsible for climate change policy and control the level of investments and emission reductions. Each agent adheres to a worldview which is located within the perspective triangle. By considering a set of similar agents who adopt various perspectives with respect to the climate change problem, the model is able to simulate the agents' adaptation of their behavior in terms of policy measures. Of course, we do not claim that realworld agents actually learn and adapt in this highly simplified way. We do, however, conjecture that there is 'weak isomorphism' between the 'Battle of Perspectives' and the ways in which real-world agents adapt to their changing environment.

Fig. 1 gives an overview of how the model experiments are set up. The population of agents is distributed across the triangle of perspectives. The real world is assumed to function according to one of the three worldviews - in this context the 'correct' worldview. This real world is observed by the agents in the form of a few indicators (atmospheric $\mathrm{CO}_{2}$ concentration $\mathrm{pCO}_{2}$ and actual temperature rise $\Delta T$ ). If the expected and the observed value of the indicator (in our case the temperature rise $\Delta T$ ) differ more than a certain tolerance level, agents may change worldview - they adapt to this 'surprise'. Hence, the dominance of worldviews, and consequently the resulting management style, change. Besides the 


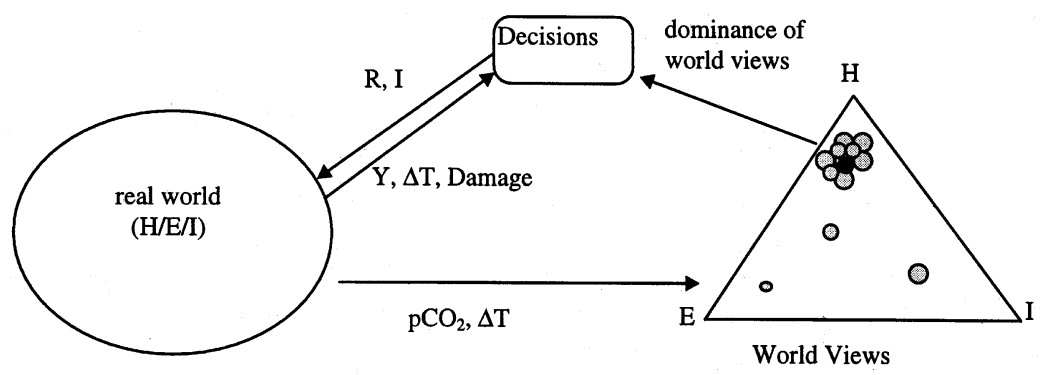

Fig. 1. Experimental set-up.

worldview, the decisions on the investment fraction $(I)$ and the emission reduction $\left(L_{\mathrm{f}}\right)$ depend on the indicators representing the state of the economy and the climate. In this paragraph we discuss the way in which we have implemented the worldview and management style in the economy-energy-climate model.

\subsection{World view}

The model described in Section 3 is assumed to represent the global system. The values of several parameters within the model are assumed to differ for the three perspectives. In conformity with the construction of the uncertainty space by Lempert et al. (1995) and sensitivity analysis by Nordhaus (1994), four items are chosen to be uncertain and controversial and hence made worldviewdependent:

- The sensitivity of the temperature for increasing $\mathrm{CO}_{2}$ concentration ('climate sensitivity').

- The pace of technological improvements in the economy and of the energy conservation transition.

- The economic costs to reduce $\mathrm{CO}_{2}$ emission ('mitigation costs').

- The economic damage incurred to the economy by climate change ('damage costs').

It should be stressed that only parameter values are changed; a more comprehensive approach would include the fact that different worldviews may actually use different models to describe the same system. For practical reasons, this is hitherto excluded.

In practical terms, this has led to worldview-dependent implementation for 7 parameters, as is shown in Table 1 and Fig. 2. The rate of technological change $a(t)$ is shown for the three perspectives in Fig. 2a. The pace of the energy efficiency transition is determined by $L_{\mathrm{e}}$ and shown in Fig. $2 \mathrm{~b}$ for the three worldviews. The values chosen for

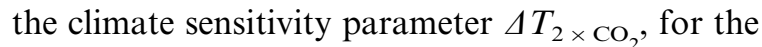
damage cost parameters $\theta_{1}$ and $\theta_{2}$ and for the emission reduction cost parameters $b_{1}$ and $b_{2}$ are given in Table 1 for the three perspectives. $L_{\mathrm{f}}$ is used as a control variable. Fig. 2c shows the development of the fossil fuel fraction for various $L_{\mathrm{f}}$ values. Of course, these implementations are not rigid and unambiguous. Within a single worldview, there are still quite distinct interpretations of what happened in the past and what is to be expected for the future.

Hierarchists are assumed to follow prominent scientific experts and institutions (such as the intergovernmental panel on climate change (IPCC)) with respect to climate-related uncertainties. They adopt the best guess or central estimate of the IPCC, $2.5^{\circ} \mathrm{C}$ for $\Delta T_{2 \times \mathrm{CO}_{2}}$ (IPCC, 1990, 1992). With regard to damage costs, the estimate given by Nordhaus (1994) is followed: a quadratic relation between temperature increase and damage cost results in a $1.3 \%$ loss of economic growth if temperature increases by $3^{\circ} \mathrm{C}$. Expectations of technological progress in the economy and with regard to energy efficiency are based on historical trends. The Hierarchist is assumed to stimulate efficiency of economic production and, therefore, a moderate value of $L_{\mathrm{e}}$ is assumed. Furthermore, as a best-guess estimate of the mitigation cost, the value proposed by Nordhaus (1994) [who based his estimates on a survey of energy models (Nordhaus, 1991)] is used. 
Table 1

Parameter values for the world view in the three perspectives

\begin{tabular}{llll}
\hline & Individualist & Hierarchist & Egalitarian \\
\hline Technological development & High & Moderate & Low \\
Climate sensitivity & Low & Best-guess & High \\
$\Delta T_{2 \times \mathrm{CO}_{2}}$ & 0.5 & 2.5 & 5.5 \\
Damage costs & Low & Moderate & High \\
$\theta_{1}$ & 0 & 0.0014 & 0.004 \\
$\theta_{2}$ & 0 & 2 & 4 \\
Mitigation costs & High & Moderate & Low \\
$b_{1}$ & 0.25 & 0.11 & 0.05 \\
$b_{2}$ & 3.5 & 2.9 & 2.3 \\
\hline
\end{tabular}

The Egalitarian myth of nature suggests that minor changes disproportionately influence the behavior of the system. Therefore, a value of $5.5^{\circ} \mathrm{C}$ for $\Delta T_{2 \times \mathrm{CO}_{2}}$ is adopted, this being one of the highest estimates to be found in the literature (Dickinson, 1986). The Egalitarian myth of nature supports the use of high cost estimates of the impacts of climate change on the human system. We assume they use a highly nonlinear damage curve, which causes a $32 \%$ loss of economic output if temperature increases by $3^{\circ} \mathrm{C}$ in the course of the next century. This value is based on the high end of the range of estimates offered by Nordhaus (1994). Egalitarians are assumed to have modest expectations about the role of technology in improving economic productivity (Fig. 2a). They do expect, however, that the threat of climate change will, in combination with carbon taxes, induce technologies which accelerate the energy efficiency transition $\left(L_{\mathrm{e}}\right)$ and the transition away from fossil fuels $\left(L_{\mathrm{f}}\right)$. They also assume that this decarbonisation of the economy can be achieved at quite modest cost per unit of reduction.

Individualists are assumed to use the lowest estimate of $\Delta T_{2 \times \mathrm{CO}_{2}}$ in the literature: a value of $0.5^{\circ} \mathrm{C}$ for $\Delta T_{2 \times \mathrm{CO}_{2}}$ (Lindzen, 1990). They also believe that no economic damage will result from climate change. If climate change occurs, technical solutions will compensate any negative effects. We assume they expect - and aspire for - a rapid pace of technology which leads to significant improvements of economic productivity $(a(t))$. In their view, the threat of climate change is unfounded or small, cheap options to improve energy efficiency are quickly used up, and the costs to develop alternatives to fossil fuels will be quite high. Hence, the energy-intensity and the carbon-intensity of the economy will fall only slowly, also because there are vast low-cost fossil fuel reserves and there is no incentive to leave them in the ground.

\subsection{Management style}

The management style refers to the crucial decisions with regard to the economy-energy-climate system. Here, these decisions are modelled as a set of simple rules. The individual agents adhere to a management style which corresponds with their worldview and which lies within the perspective triangle. During the simulation period, the preferred management style of each perspective is determined every year. The weighted average of the perspective adhered to by the individual agents determines the policy that is implemented c.q. the values of investment ratio $I$ and fossil fuel transition parameter $L_{\mathrm{f}}$.

The decisions forming a management style are made on the basis of discrepancies between expected and observed behavior of the system. The assumptions which are made in framing decision rules are mainly based on Schwartz and Thompson (1990), Thompson et al. (1990), Rayner (1991). We proceed with a description of the decision rules which make up a management style; the three management styles are summarized in Table 2 . 

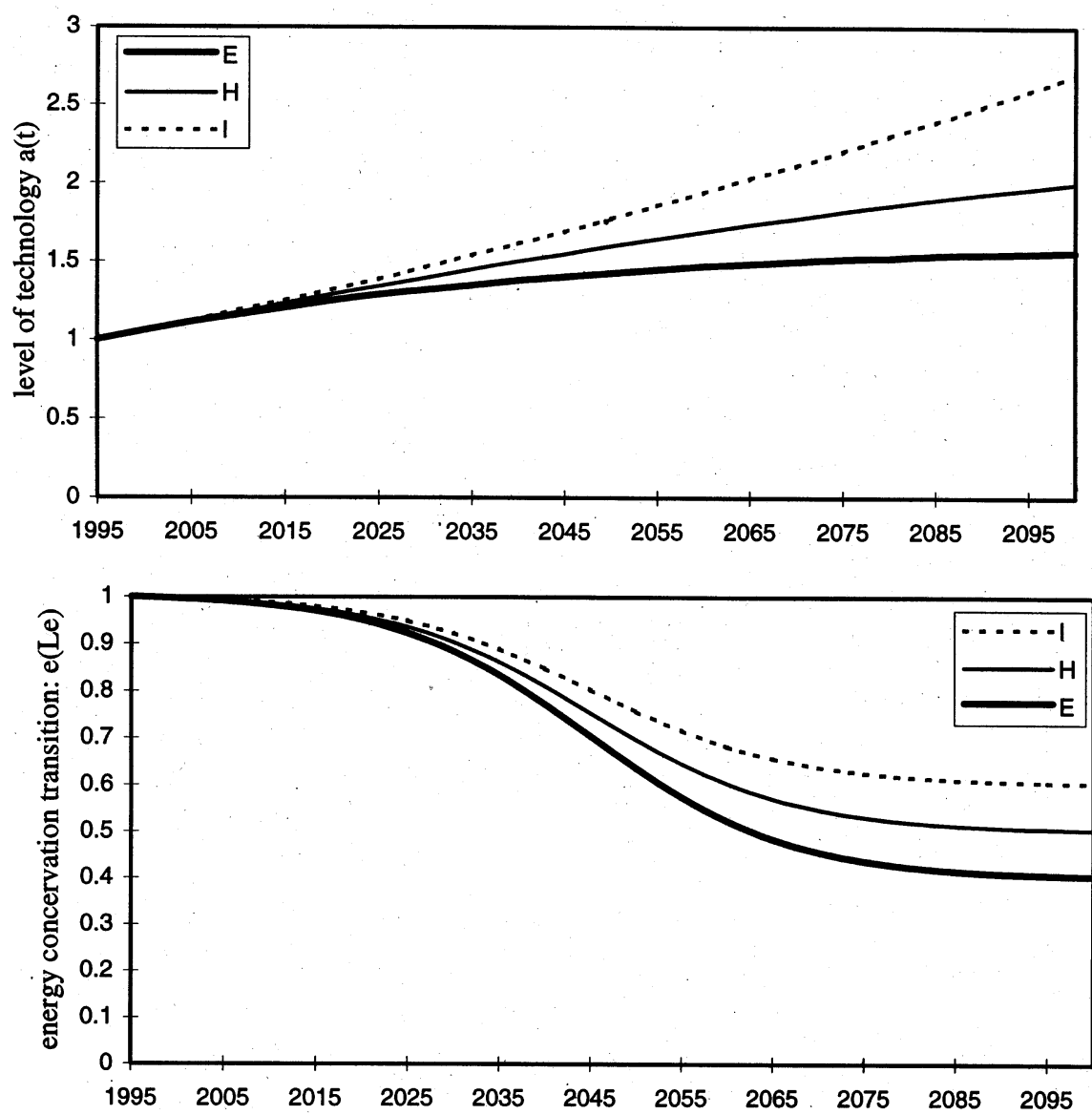

b

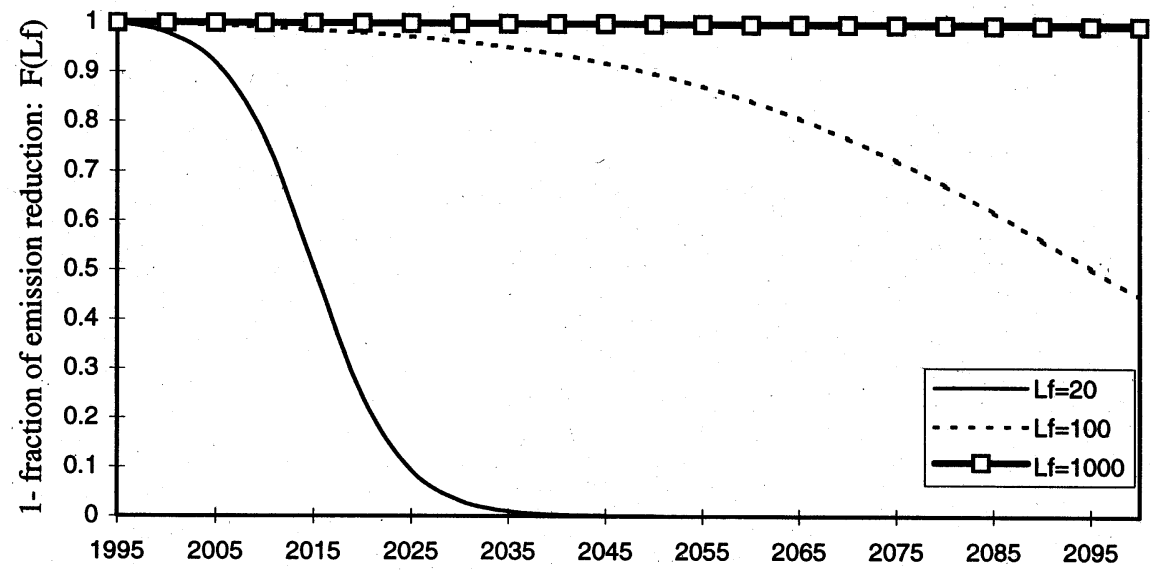

c

Fig. 2. Trajectories of the technological development parameter (a), the energy efficiency transition (b) and the fossil fuel transition (c) as implemented for the three perspectives. 
Table 2

Decision rules characterising the three management styles

\begin{tabular}{|c|c|c|c|}
\hline & Individualist & Hierarchist & Egalitarian \\
\hline $\begin{array}{l}\text { Investment deci- } \\
\text { sions }\end{array}$ & At least $2 \% / \mathrm{yr}$ growth of $Y$ & $\begin{array}{l}\text { Stable economic growth of } 1.5 \% / \\
\mathrm{yr}\end{array}$ & No expansion of capital stock \\
\hline $\begin{array}{l}\text { Indicator for cli- } \\
\text { mate policy }\end{array}$ & Damage cost & Temperature & Emissions \\
\hline Climate policy & $\begin{array}{l}\text { If damage }>1 \% \text { of } Y \text { than de- } \\
\text { crease } L_{\mathrm{f}} ; \text { otherwise } L_{\mathrm{f}}=1000\end{array}$ & $\begin{array}{l}\text { If temperature rise decrease } L_{\mathrm{f}} \text {; } \\
\text { otherwise } L_{\mathrm{f}}=100\end{array}$ & $\begin{array}{l}50 \% \text { reduction of fossil fuels in } 20 \\
\text { years: } L_{\mathrm{f}}=20\end{array}$ \\
\hline
\end{tabular}

The preferred management style of Hierarchists is one of control and reliance on experts. They are keenly aware of the social instability which may result from stagnating economic growth. In the trade-off between the stimulation of economic growth and diminishing the risk of long-term climate change, they will be led by cost-benefit analyses. In our model, this is operated by assuming that Hierarchist institutions aim for a desired growth rate of economic output, $\mathrm{d} Y_{\mathrm{D}}$, which in a world without climate change risks would give a smooth expansion of the economy:

$I^{H}(t)=0.9 \cdot I(t-1)+0.1 \cdot \frac{\mathrm{d} Y_{D}}{\mathrm{~d} Y(t-1)} \cdot I(t-1)$

With this formulation, the preferred level of investments is a function of the level of investments of the previous year and abrupt changes in the investment levels are avoided. Investments will grow at the same rate as $Y / a$ unless part of the output is lost through climate change damage or is spent on emission reduction. If the world behaves as the Hierarchist believes, i.e. according to the Hierarchist worldview, model experiments indicate that the desired economic growth level can be about $1.5 \% / y r$. If it exceeds this value, economic output will start to fall before the year 2100 , the time horizon of our simulations. Hence, we have set $\mathrm{d} Y_{\mathrm{D}}=1.5 \% / \mathrm{yr}$.

Hierarchists are aware of the social and economic risks involved if the climate changes. However, as long as the observed temperature increase is below $0.5^{\circ} \mathrm{C}$, Hierarchist institutions are assumed not to react and the fossil fuel transition is rather slow $\left(L_{\mathrm{f}}=100\right.$ years; Fig. $\left.2 \mathrm{c}\right)$. They are willing to act as soon as the rate of temperature change exceeds this threshold level. When the observed temperature increase relative to 1995 , $\mathrm{d} T_{\text {obs }}$, exceeds the $0.5^{\circ} \mathrm{C}$ increment, the substitution of fossil fuels by non-carbon based alternatives will be accelerated, Below the $1.0^{\circ} \mathrm{C}$ level, the transition is only slightly speeded up; above it, but below the $1.5^{\circ} \mathrm{C}$ level, it is accelerated with nearly 1 year per year. In formula form:

$$
\begin{gathered}
\text { if } \mathrm{d} T_{\text {obs }}<0.5 \\
\text { then } L_{f}=100 \\
\text { if }\left(0.5<\mathrm{d} T_{\text {obs }}<1.0\right) \\
\text { if }\left(1.0<\left(L_{f}(t-1)-20\right) \cdot 0.995\right. \\
\text { obs }<1.5) \\
\text { then } L_{f}(t)=20+\left(L_{f}(t-1)-20\right) \cdot 0.99 \\
\text { then } L_{f}(t)=20+\left(L_{f}(1.5\right. \\
\text { then } L_{f}(t)=20+\left(L_{f}(t-1)-20\right) \cdot 0.98
\end{gathered}
$$

We assume an upper level of a temperature increase of $2^{\circ} \mathrm{C}$ relative to 1900 , a number based on the UNEP's Advisory Group on Greenhouse Gases (AGGG, 1990). It is also assumed that $L_{\mathrm{f}}$ cannot become $<20$ years. The particular set of decision rules is determined by model experiments in which the worldview is Hierarchist ('the Hierarchist utopia') and with a maximum temperature of $1.5^{\circ} \mathrm{C}$ (Section 4.4).

From an Egalitarian perspective the management style should be based on the precautionary principle. In order to guard the society against a full-blown catastrophe in the long term, drastic structural social, cultural and institutional changes are necessary, notwithstanding short-term disadvantages and costs. With respect to climate policy, this implies a rapid transition towards a fossil free society. In our model, we assume that 
$L_{\mathrm{f}}=20$ years. In line with the emphasis on more evenly distributed wealth and income and on less materialistic values, the Egalitarian management style aims at zero economic growth. Indeed, the only growth of economic output results from population growth and technological progress (a; Table 1 and Fig. 2a). This is done in the model with the rule that investments equal the depreciation rate of existing capital goods (see Eq. (2)):

$I^{E}(t)=\frac{\delta_{k} \cdot K(t-1)}{Y(t-1)}$

Individualists prefer the market mechanism as the management instrument par excellence. This often implies an adaptive management style. Disturbance of the climate system will provide new opportunities for smart entrepreneurs; government-based climate policies are not needed or even harmful. The individualist outlook supports a high rate of economic growth. Only if the monetary damage becomes a noticeable fraction of economic output will they start to implement energy policy measures. The basic decision rule we implemented is, in formula form:

if $\mathrm{d} Y(t)<\min [\mathrm{d} Y]$ then $I^{I}(t)=$

$\min \left(1.0, \min [\mathrm{d} Y] \cdot \frac{I(t-1)}{\mathrm{d} Y(t-1)}\right)$

$\operatorname{else} I(t)=I(t-1)$

where $\min [\mathrm{d} Y]$ is the minimum economic growth preferred by the individualist. A simple adaptive strategy is assumed: if economic growth falls below a certain desired minimum level, investments are increased. The value of the minimum growth rate is determined by model experiments with an Individualist worldview ('the Individualist utopia', see Section 4.4). In such a world, the value of $\min [\mathrm{d} Y]$ has to be set at $2 \% / y r$ to avoid a collapse in consumption per capita before the end of the next century. As to emission reduction, the Individualist will follow an adaptive strategy which is based on damage costs: if damage costs exceed a certain threshold value, in our model set at $1 \%$ of economic output, the fossil fuel transition is accelerated quite effectively towards the rate of minimum half-life time of 20 years. This approach is somewhat similar to that adopted by Lempert et al. (1995). Thus:

$L_{f}^{I}=20+\left(L_{f}^{I}(t-1)-20\right) \cdot 0.99$

As long as no significant economic damage is detected, the half-life time of a fossil transition is assumed to be the longer period of 1000 years.

\subsection{Utopias and dystopias}

Let us first look at the situation when the world is inhabited by agents which have one, shared perspective on how the world functions and how it should be managed. Indeed, this assumption of a single 'global commoner' is made in almost all studies on climate change. If we indicate such a future as $\mathrm{XY}$ with $\mathrm{X}$ denoting the worldview, $\mathrm{Y}$ the management style and $\mathrm{X}, \mathrm{Y}$ either the Hierarchist $(\mathrm{H})$, the Egalitarian (E) or the Individualist (I), the three so-called utopias are HH, EE and II. We briefly discuss these utopias because they have been instrumental in designing and implementing the management styles (Section 4.3).

A utopia is characterized by the fact that the worldview is correct and that the management style of the single agent is in agreement with this worldview. Such an agent adopts a perspective which is located in one of the corners of the triangle of perspectives. The development paths of the three utopias are given in Fig. 3 for three variables: economic output $(Y)$, fossil $\mathrm{CO}_{2}$ emissions $(E)$ and temperature change $(\Delta T)$. In the Egalitarian utopia, economic growth is approximately $1 \% / \mathrm{yr}$ and the $\mathrm{CO}_{2}$ emissions from fossil fuel combustion start falling after 2005 because of the policy to accelerate the fossil fuel transition. As a result, there is only a modest temperature increase of $0.5^{\circ} \mathrm{C}$ although the Egalitarian worldview holds that the climate system is quite sensitive.

In the Hierarchist utopia, the economy grows at a stable rate of $1.5 \% / \mathrm{yr}$. The $\mathrm{CO}_{2}$ emissions keep increasing and so does the temperature change. However, the Hierarchist management style responds to the rising temperature by accelerating the phasing out of fossil fuels and the temperature increase can be stabilized at about $1.5^{\circ} \mathrm{C}$ above present values. This is assumed to be in the upper range of what is considered acceptable in many 

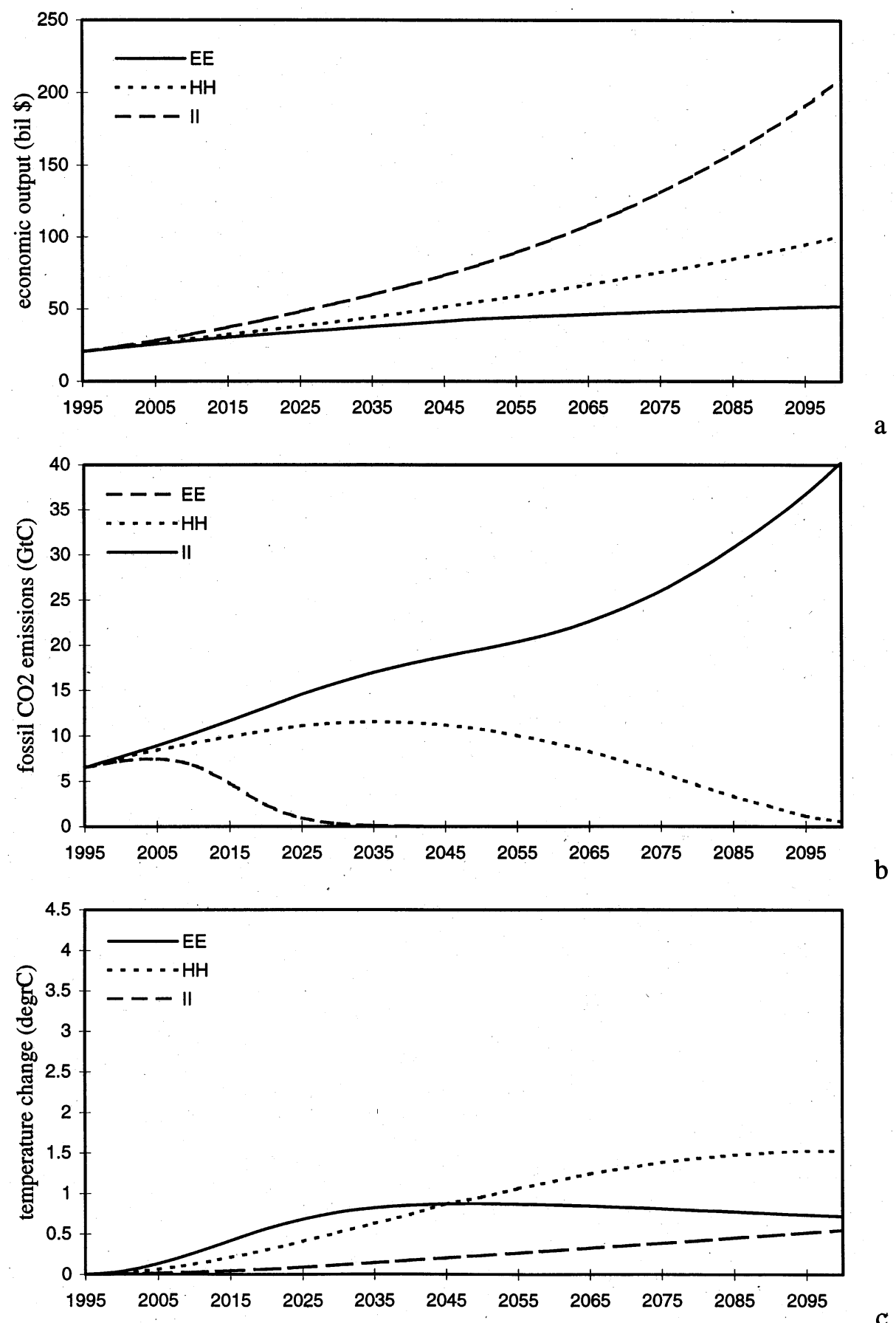

Fig. 3. Utopia projections if the world functions according to the world view of an Egalitarian ( -$)$, hierarchist (...) or individualist $(-)$, and the agents do not learn and adapt. 

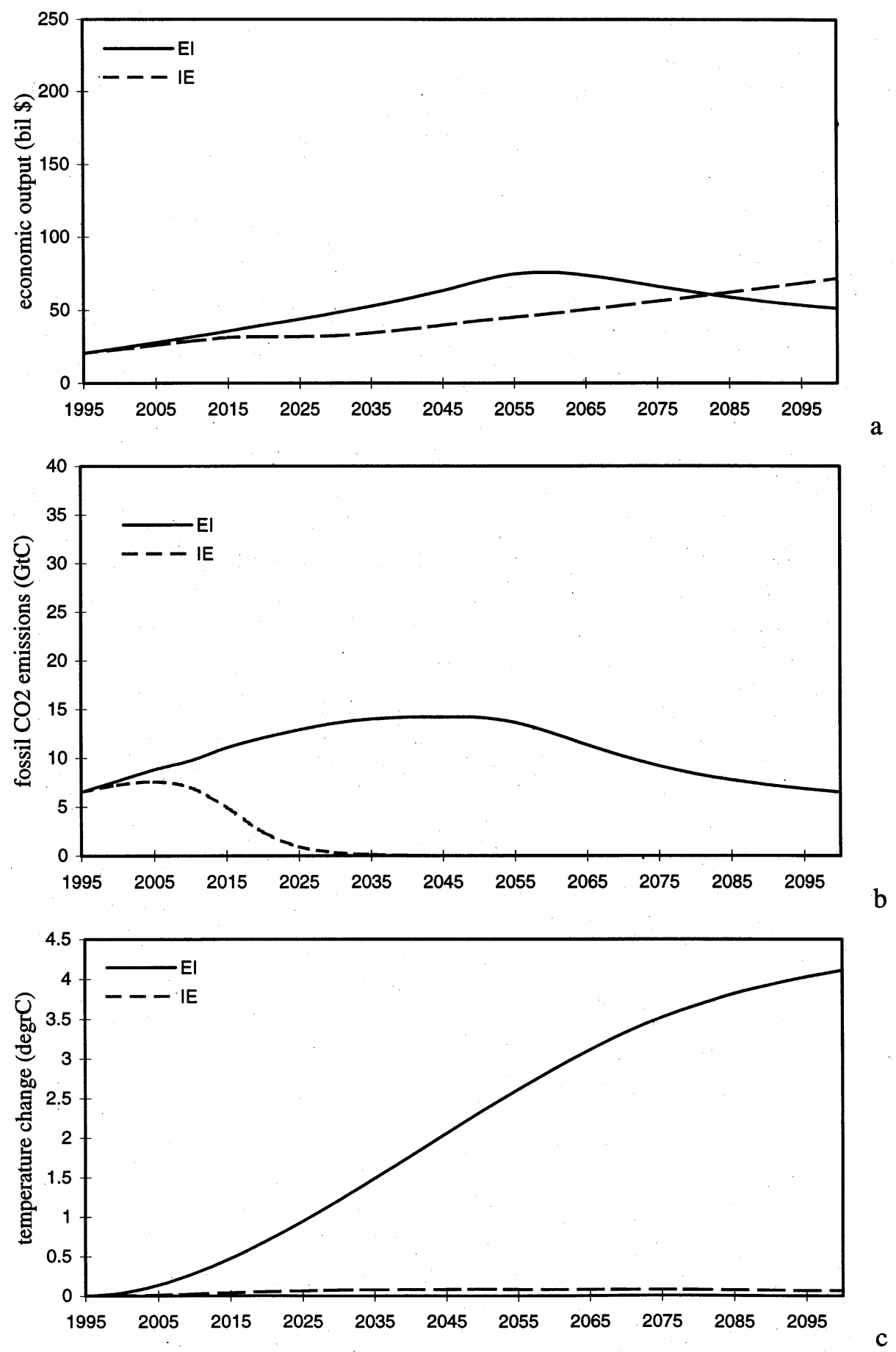

Fig. 4. Dystopia projections EI and IE. 
official studies. In the Individualist utopia, economic growth is greater than $2 \% / y r$ throughout the next century. As the Individualist expects only a modest decline in energy intensity, $\mathrm{CO}_{2}$ emissions soar to over $40 \mathrm{GtC}$ in 2100 . In the Individualist worldview, the climate system is also believed to be quite insensitive to human disturbances and hence these high emissions cause only a small increase in the global temperature of $0.5^{\circ} \mathrm{C}$ in 100 years. This temperature change has no significant impact on economic activities, so that there is no policy response and the use of fossil fuels is not restricted.

Interesting situations emerge if the worldview and the management style are not in agreementdystopias. Fig. 4 presents for the same three model variables in the two most interesting dystopias. The first is when the correct worldview is Egalitarian, i.e. the climate system is quite sensitive, but economic aspirations and feedbacks to temperature rise are based on an Individualist management style (scenario EI). In this situation, with the system functioning according to the Egalitarian world view, an Individualist management style leads to a collapse in economic development due to high economic growth aspirations together with severe impacts of climate change. The emission reduction measures are implemented at too late a juncture to avoid a temperature increase in excess of $4^{\circ} \mathrm{C}$. This dystopia is the one which has been sketched regularly by environmentalist groups who fear that the prevailing economic growth aspirations will spell environmental catastrophe.

The second case is when the Egalitarian management style is adopted by the governing agent, and subsequently turns out to be unnecessary because the climate system is quite robust with respect to human activities (IE). An Egalitarian management style implies low economic growth and an acceleration of the fossil fuel transition at a cost. The resulting reduction of $\mathrm{CO}_{2}$ emissions leads to a stabilization of the temperature increase. As the climate turns out to be rather insensitive, the rise in temperature is confined to a mere $0.1^{\circ} \mathrm{C}$ (Fig. 4). This combination of an Individualist worldview and an Egalitarian management style can be seen as a world in which environmentalists gain enough popular support to dictate growth-restraining policies. Individualist-oriented business people will claim that climate change is still scientifically controversial and fear that all these measures are a waste of money. In this dystopia, they turn out to be right: economic growth is suppressed whereas no or acceptable climate risks would have been run in a high-growth development path.

\section{Changing perspectives and adaptive behavior}

\subsection{Introduction}

The 'global commoner' in these utopias and dystopias has an important characteristic: [s] he does not learn from observations about how the real-world actually behaves. In the case of a utopia, the world fits one's expectations and no learning and adaptation are needed. However, in the case of a dystopia there is a mismatch between expectations and observations. It is probable - and desirable - that the agent is able to learn and adapt so as to avoid a disastrous dystopia instead of rigidly sticking to its unfolding. Here, the 'Battle of Perspectives' come into the picture.

According to Thompson et al. (1990), people are assumed to abandon their perspectives in the event of surprise, that is, if observations differ from expectations. People who adhere to a certain worldview will switch to another one if it can better explain the observed behavior of the system. This learning and adaptive behavior of agents is simulated in the 'Battle of Perspectives' by using a genetic algorithm. To this end, we define the equivalent of 50 agents and distribute the management styles among them in the form of the previously described decision rules. The number of 50 agents is chosen because we want the model to be interactively used and too many agents would cost too much computation time. Too few would not give enough requisite variety. In our simple modelworld, the feedback is implemented by having the agents compare the observed temperature change with the expected one (Fig. 1). The expected temperature change for perspective $\mathrm{i}, \Delta T_{\text {exp }, \mathrm{i}}$, is given by:

$$
\Delta T_{\mathrm{exp}, \mathrm{i}}(t)=\frac{\Delta T_{2 \times \mathrm{CO}_{2}}}{\ln (2)} \cdot \ln \left(\frac{p \mathrm{CO}_{2_{\mathrm{obs}}}(t)}{p \mathrm{CO}_{2_{1995}}}\right)
$$




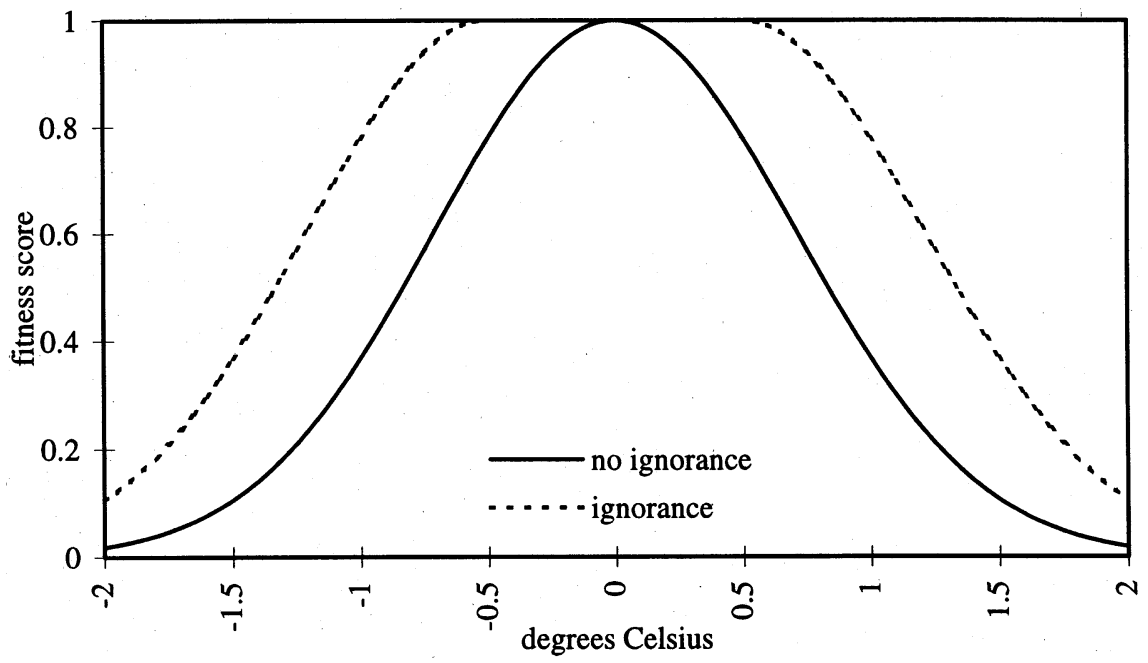

Fig. 5. Fitness function of agents' perspective related to the mismatch in expectations and observations. For ignorance tol $=0.5$ is used and for no-ignorance tol $=0$ is used.

where $\Delta T_{2 \times \mathrm{Co}_{2}}$ is the climate sensitivity according to the perspective of the agent (Table 1) and $\mathrm{pCO}_{2}$ obs is the measured concentration of $\mathrm{CO}_{2}$. The next step is that we define a fitness function which is a measure of how well the system behavior for a given management style fits with the real-world observations. Given the way we have implemented the feedback, this fitness function is a function of the expected temperature change resulting from the observed $\mathrm{CO}_{2}$ concentration and the observed temperature change. The larger the discrepancy between the observed and the expected $\Delta T$, the less fit the management style is with regard to the real-world system. Evidently, there is no empirical basis for such a fitness function. To initialize the system in a transparent way, we assume that one of the 'extreme' agents has the correct model of the system.

For those agents who hold the correct view of the climate system, the observed temperature change will be approximately equal to the expected global mean temperature change. If their worldview is incorrect, the observed and the expected value will diverge. As long as this difference between the two is less than a tolerance level, $\tau$, the fitness of the agents' perspective is assumed to be maximal and the agents have no reason to alter their perspective. This tolerance level is in- cluded to take account of the fact that perfect insight is not possible. We refer to it as 'ignorance'. In our model simulations, the existence of a certain ignorance causes a delay in the learning and adaptive behavior of the agents. In the event of a difference between the observed and the expected temperature change which exceeds this tolerance level, the agents are surprised and motivated to alter their perspective.

The fitness function used is shown in Fig. 5. If the observed value $\Delta T_{\text {obs }}$ is smaller than the expected value minus the tolerance level $\left(\Delta T_{\text {obs }}<\right.$ $\left.\Delta T_{\text {exp }, \mathrm{i}}-\tau\right)$ or larger than the expected value plus the tolerance level $\left(\Delta T_{\text {obs }}>\Delta T_{\text {exp }, \mathrm{i}}+\tau\right)$, the fitness of the corresponding worldview and management style decreases:

$f_{i}=\exp \left(-a b s\left(\Delta T_{\mathrm{ep}, \mathrm{i}}-\Delta T_{\mathrm{obs}}-\tau\right)^{2}\right)$

The genetic algorithm and the dynamic system are integrated in the following manner. In scenario analysis a model as described in Section 3 simulates the effects of assumptions made for the control rates $I$ and $L_{\mathrm{f}}$. In an optimization approach, the optimal values of the control rates $I$ and $L_{\mathrm{f}}$ are determined. In this 'Battle of Perspectives', the control rates are a function of the state variables. The values $I$ and $L_{\mathrm{f}}$ are the (weighted) averages of $I_{i}$ and $L_{f i}$, the agent-specific values for 

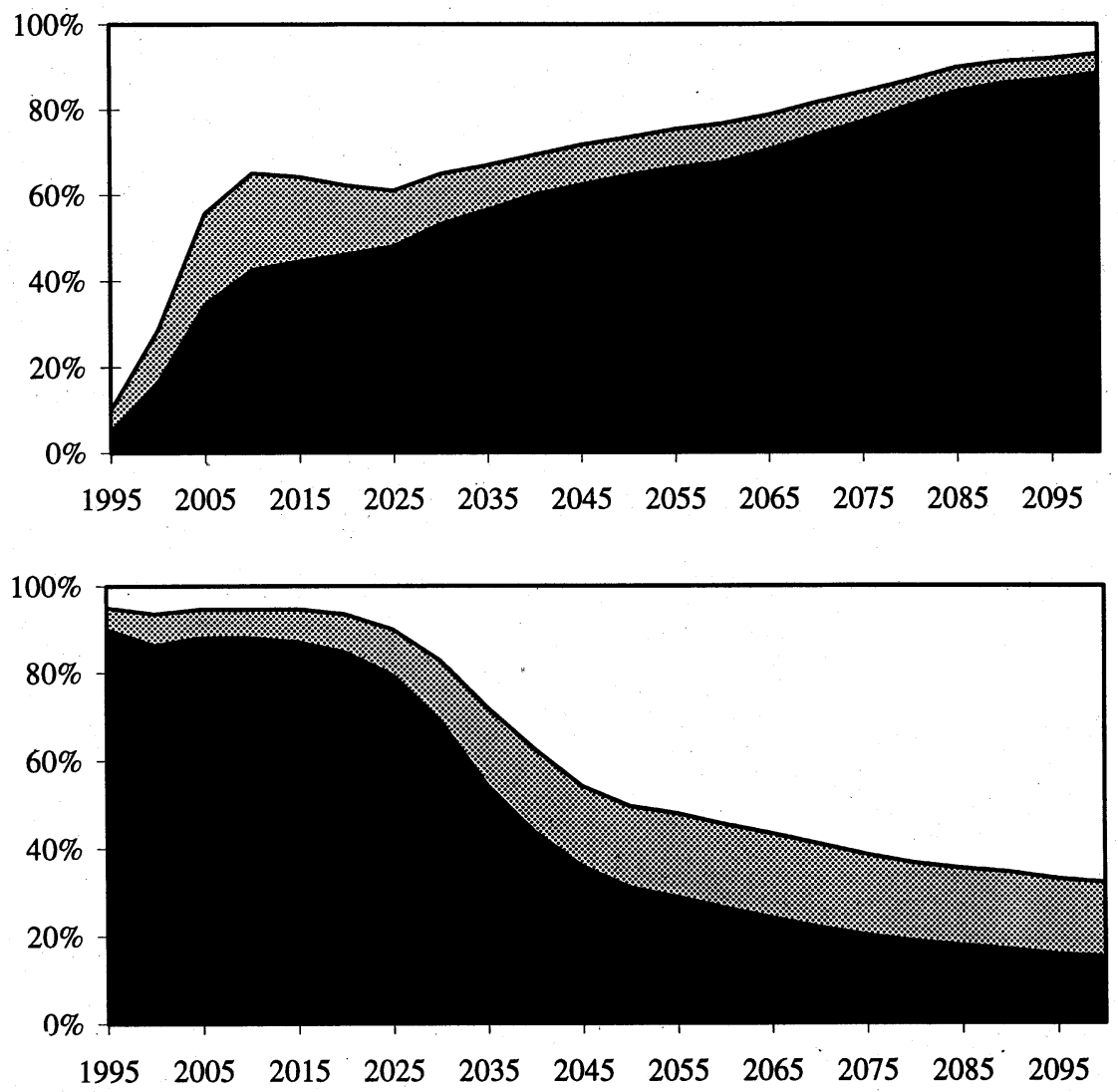

Fig. 6. Changes of perspectives in case adaptive agents are confronted with a EI (a) or a IE (b) dystopia: $\square$, Individualist; Hierarchist; $\mathbf{\square}$, Egalitarian.

the control variables. These values may change, in time, due to changes in the system. For example, if the dominant perspective of the agents concerned is individualist at the start, it may change in reaction to a persistent series of surprises into a more Hierarchist or Egalitarian perspective.

The experiments are performed for the three sets of assumptions on how the real-world climate system functions: Hierarchist, Egalitarian and Individualist. For each experiment, 100 runs are performed because of the (stochastic) adaptation of the agents' perspectives. Assuming each of the 100 runs as an equally probable future, we can consider the average outcome as an expectation. Here, we only discuss these average expectations (Janssen, 1996). The starting situation is comparable with the utopias and dystopias discussed in the previous section: a dominating management style $X$ in a world which functions according to perspective Y. However, the agents' perspectives may now change in time, looking for the best explanation of the observations, and none of the perspectives fully determines the climate change policy. A tolerance level of $0.5^{\circ} \mathrm{C}$ is used as a measure for ignorance.

\subsection{Model experiments}

We will discuss the dystopian cases of Section 4.4 , but now including adaptive behavior of the agents. In Fig. 6 the adaptation dynamics are depicted in terms of the changing distribution of agents among the three perspectives. Although the dominance between the perspectives changes, 


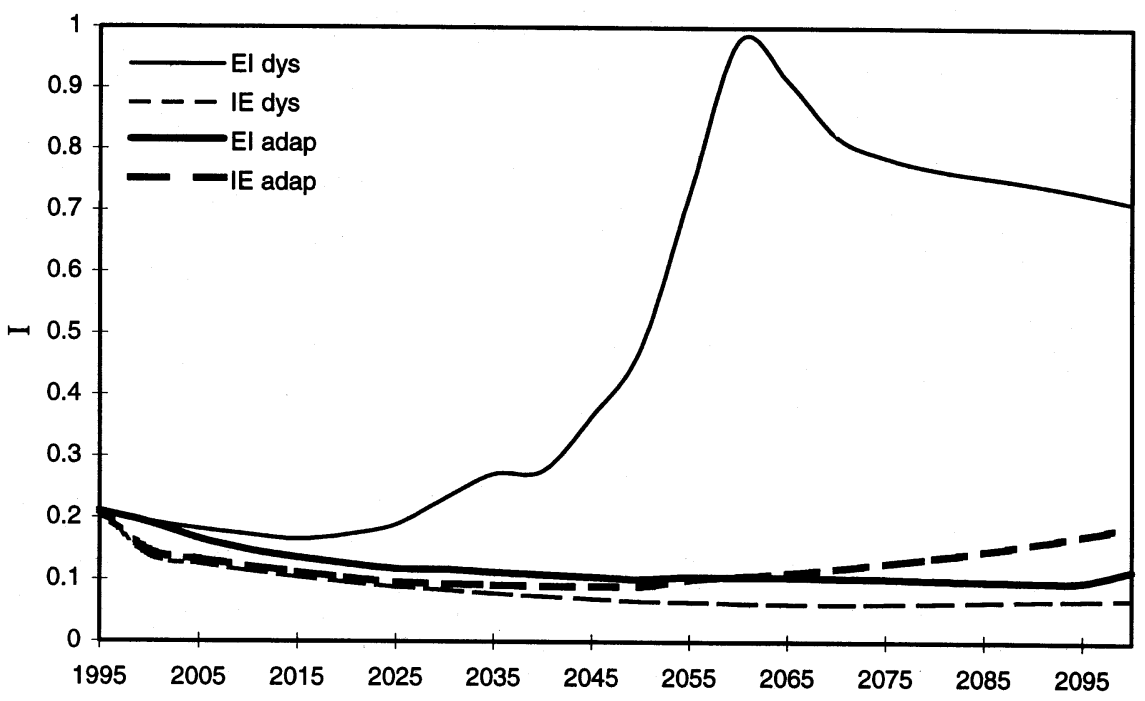

a

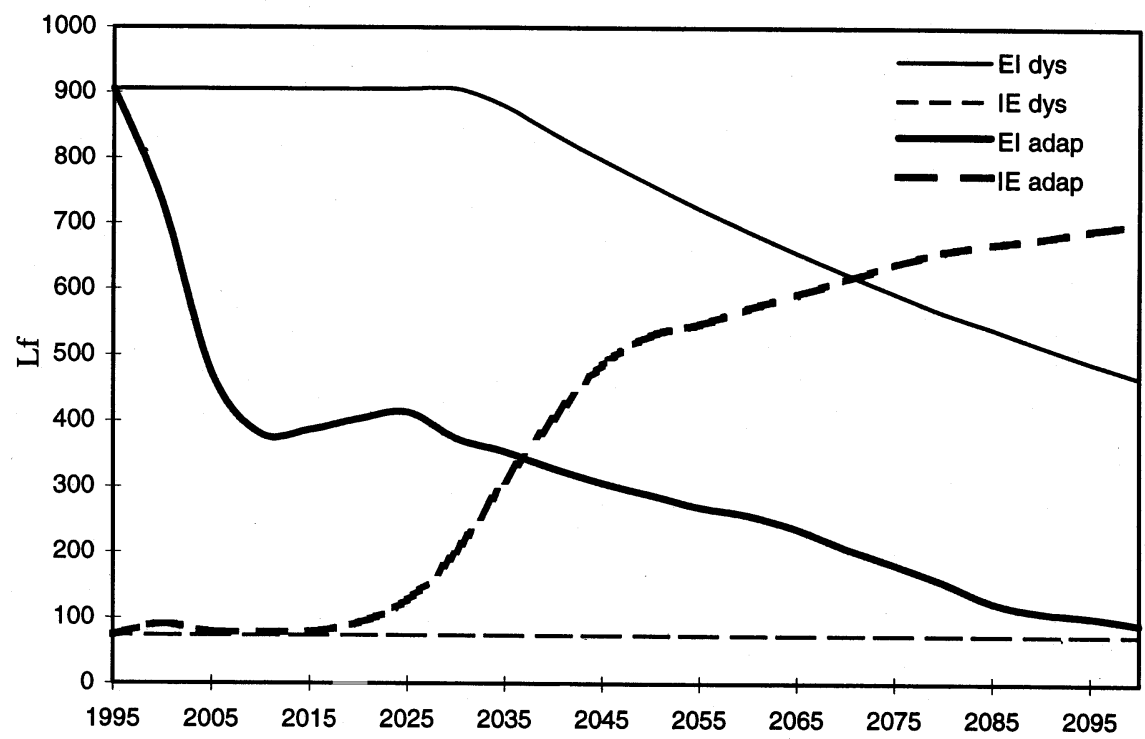

b

Fig. 7. The values of responses $I$ (savings rate) and $L_{\mathrm{f}}$ (half-time fossil fuel transition) for the dystopias (dys) and for the case agent adapt to dystopias (adap).

there will always be room for each of them. The changing perspective prevents the system from following the extreme trajectories of the dystopias (Fig. 4).

In the case of a non-adaptive Individualist management style and a world functioning according to the Egalitarian worldview (EI), the investments to meet the high growth aspirations become excessively high as more and more output is lost to damage from climate change (Fig. 7(a)). However, in the case of adaptation, this is not happening because the phasing out of fossil fuels is accelerated and $\mathrm{CO}_{2}$ emissions are significantly curbed (Fig. 7b; Fig. 8b vs. Fig. 4b). As a consequence, economic output peaks at a 50\% lower level. Despite these adaptive measures, the result- 

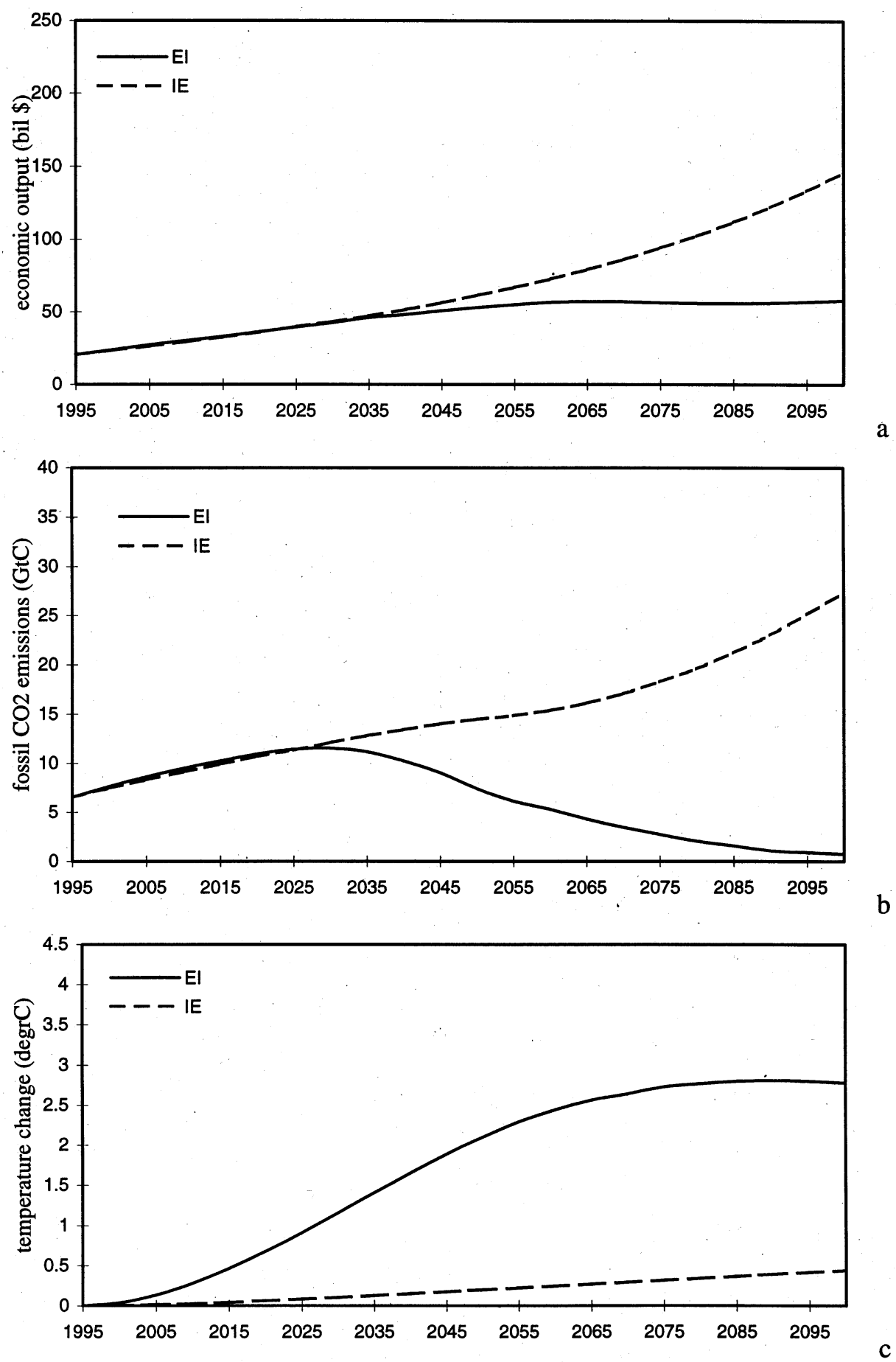

Fig. 8. Projections if adaptive agents are confronted with a EI or IE dystopia. 
ing drop in the anticipated temperature rise of $1^{\circ} \mathrm{C}$ by 2100 still does not bring the system in the low risk area: the global average temperature increase still amounts to almost $3^{\circ} \mathrm{C}$ at the end of next century (Fig. 8c vs. Fig. 4c). This simulation shows that a world with adaptive agents leads to significantly lower $\mathrm{CO}_{2}$ emissions, but the dynamics as implemented in our model are too slow to bring the temperature change and the resulting climate change risks down to the levels of the Egalitarian utopia (Fig. 3).

The other dystopia represents the combination of an Egalitarian management style and an Individualist worldview (IE). Due to adaptation, the initial desire for a fast but costly change to a fossil free society becomes less dominant as the stringent Egalitarian measures are increasingly proven to be unnecessary. In such a world which functions according to the Individualist worldview, there will be an almost twice as high economic output and also a higher temperature increase compared with the dystopian case (Fig. 8a vs. Fig. 4a). This scenario is a real 'middle-of-the-road' course: the high growth levels of the Individualist utopia are not reached, but the temperature rise remains significantly below the level of the Egalitarian utopia (Fig. 3(a-c)).

\subsection{Surprises}

Climate change researchers are regularly confronted with new surprises. For example, in recent years new scientific findings (IPCC, 1992, 1996a,b,c) have shown that: (a) negative radiative forcing due to ozone depletion could counteract positive radiative forcing associated with chlorofluorocarbons (CFCs); (b) there is a possible cooling effect due to aerosols resulting from sulfurous emissions; (c) the rates of increase in the atmospheric concentration of most greenhouse gases have slowed down.

Imagine a world in which serious global warming may occur due to human activities. Suppose, furthermore, that this is a world in which the Egalitarian perspective dominates at the start and agents do not ignore differences between observations and measurements. Now, by the middle of next century, it is found that the global mean temperature has been suppressed by a temporary cooling effect due to the emissions of sulfur oxide. As a result, the expected temperature for all three perspectives is lower than what should be expected on the basis of a correct worldview including the cooling effect. When the 'mask' falls off in the middle of the next century, the various agents are confronted with a surprise. How well would this world adapt to this surprise?

The cooling surprise would lead to a slowingdown of emission reduction, due to greater dominance of the Hierarchist and Individualist perspectives (Fig. 9). This results in an additional increase of about $1^{\circ} \mathrm{C}$ by 2100 , although this increase is not recognized before the middle of the next century. Initially, the Hierarchist and Individualist perspective gain more followers than without the surprise; later on, when the cooling effect is acknowledged, the proportion of those who adhere to the Egalitarian perspective increases. However, in our agent implementation and choosing the year 2050 as the date of discovery, this adaptive response is too slow to a significantly higher temperature rise than would have occurred without the surprise. This experiment illustrates that a delayed response not only leads to a later reduction of emissions, but also that due to a lock-in of an Individualist management style, the needed emission reductions are implemented more slowly and lead to an additional response delay.

\section{Conclusions}

The 'Battle of Perspectives' is meant as an illustration of the use of evolutionary modelling in incorporating human behavior within integrated assessment modelling. It simulates, within the framework of utopian and dystopian scenarios, the role of adaptive change by agents who learn from their observations of the real world. Obviously, the results are tentative in view of the many uncertainties inherent to the implementation of worldviews and decision rules for the chosen three characteristic agents. We do feel, however, that some basic aspects of the learning and adaptive behavior presented here are operating in the real world. 

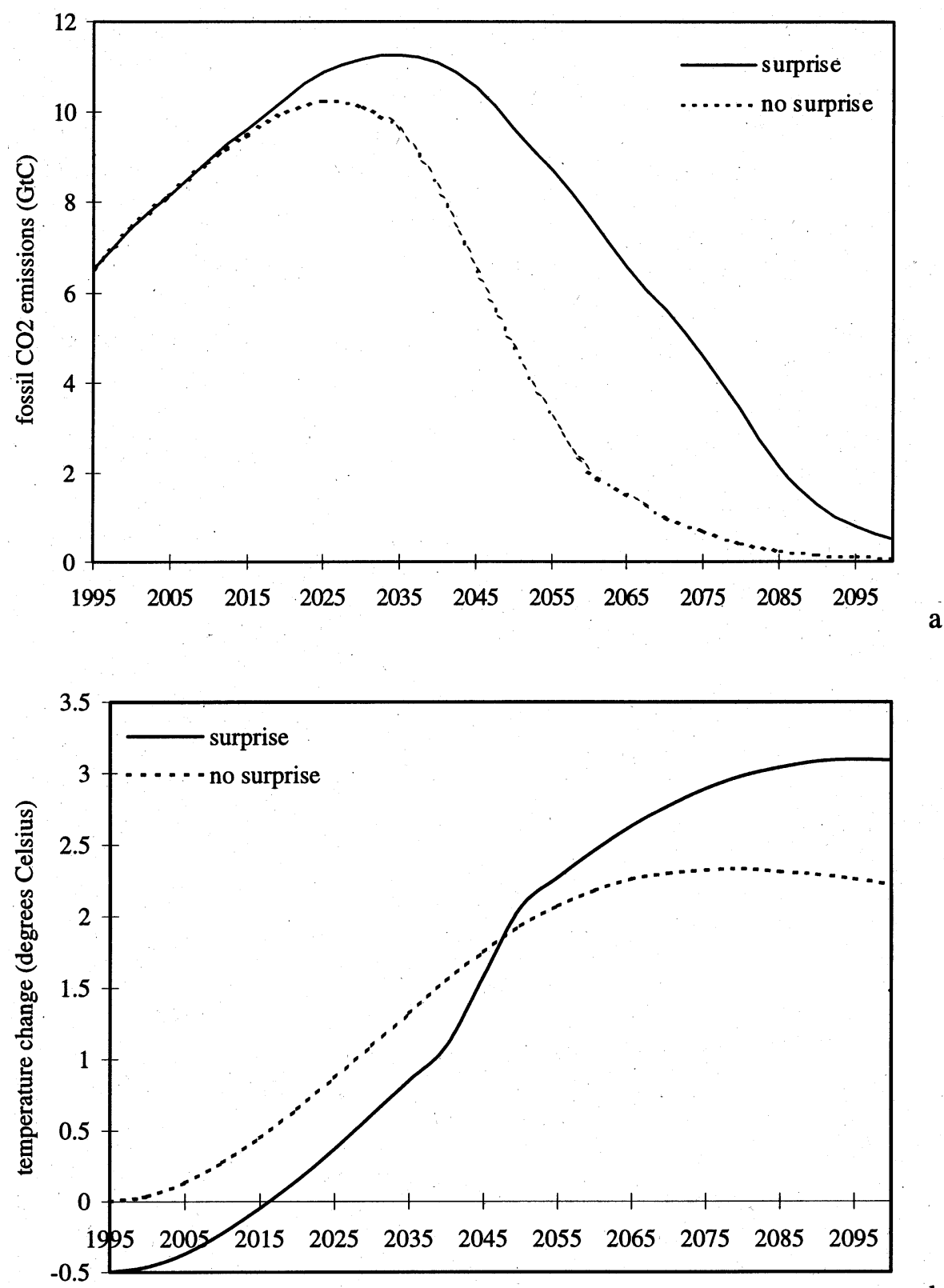

b

Fig. 9. (a) Average projections of fossil $\mathrm{CO}_{2}$ emissions if the agents are confronted with a (cooling) surprise or not. (b) Average projections of temperature change of the agents are confronted with a (cooling) surprise or not.

Given these caveats, the following conclusions can be drawn. Our approach enables a more explicit treatment of the notions of social change and scientific surprise events than earlier modelling activities in the field of integrated assess- ment for global climate change. Instead of projecting images of the future in terms of scenarios with exogenous or optimal policies, we are able to demonstrate the possible relevance of learning and adaptation. The Cultural Theory 
provides a helpful framework to organize the experiments; genetic algorithms are a useful tool to implement the approach.

The results show that, in a world in which climate change is the only problem to worry about, the learning of agents from observations in the form of a changing mix of aspirations and policies could make quite a difference for the future. It would play minor role in a utopian world in which knowledge is perfect. However, in the real world with its imperfect knowledge, it could be of decisive importance in a situation in which dystopian tendencies would bring the world close towards catastrophe. Our research demonstrates that a more thorough understanding of the role of ignorance and the features of social dynamics, as displayed nowadays in the international negotiations to reach a climate treaty, could add realism to and reduce the uncertainty in the plethora of published emission scenarios. It would also provide a healthy impetus to social scientists to participate in the important debate about how to anticipate and respond adequately to this possibly major threat which faces humankind.

\section{Acknowledgements}

We would like to thank Jan Rotmans, Jodi de Greef, Michael Thompson, Frank Geels, Arie Rip, Dale Rothman, Robert Lempert and Paul Taylor for their comments and stimulating discussions on earlier versions of this paper.

\section{References}

AGGG, 1990. Targets and Indicators of Climate Change. In: Rijsberman and Swart (Eds.), Report of Working Group II of the Advisory Group on Greenhouse Gases (AGGG), Stockholm Environmental Institute, Stockholm, Sweden.

Bossel, H., Strobel, M., 1978. Experiments with an 'intelligent' world model, Futures, June, 191-210.

Bulatao, R.A., Bos, E., Stepens, P.W., Vu, M.T., 1990. World Population Projections 1989-1990 Edition: Short and Long-Term Estimates. The John Hopkins University Press. Baltimore (published for the World Bank).

De Vries, H.J.M., Janssen, M.A., 1996. Global energy futures: An integrated perspective with the TIME model, RIVM report 461502018, Bilthoven, the Netherlands.
Dickinson, R.E., 1986. How will climate change? The climate system and modelling of future climate. In: Bollin, B, Döös, B.R., Jäger, J., Warrick, R.A. (Eds.), The Greenhouse Effect, Climate Change and Ecosystems. SCOPE 13, John Wiley, Chichester, UK, pp. 206-270,

Epstein, L.M., Axtell, R.L., 1996. Growing Artificial Societies: Social Science from the Bottom-up. Brookings Institution, Washington, USA.

Goldberg, D., 1989. Genetic Algorithms in Search, Optimization, and Machine Learning. Addison-Wesley, Reading, MA.

Hammitt, J.K., Lempert, R.J., Schlesinger, M.E., 1992. A sequential-decision strategy for abating climate change. Nature 357, 315-318.

Holland, J.H., 1975. Adaptation in Natural and Artificial Systems. MIT University of Michigan Press, Ann Arbor.

Holland, J.H., Miller, J.H., 1991. Artificial Adaptive Agents in Economic Theory. AEA papers and Proceedings, May, $365-370$.

Holland, J.H., 1992. Genetic algorithms. Sci. Amer. July, 44-50.

Hourcade, J.C. et al., 1995. A review of mitigation cost studies. In: IPCC, Economic and social dimensions of climate change, Cambridge University Press.

IPCC, 1990. In: Houghton, J.T., Jenkins, G.J., Ephraums, J.J. (Eds.), Climate Change: The IPCC Scientific Assessment. Cambridge University Press.

IPCC, 1992. In: Houghton, J.T., Callander, B.A., Varney, S.K. (Eds.), Climate Change 1992: The Supplementary Report to The IPCC Scientific Assessment. Cambridge University Press.

IPCC, 1996a. Climate Change 1995: The Science of Climate Change. Cambridge University Press.

IPCC, 1996b. Climate Change 1995: Impacts, Adaptations and Mitigation of Climate Change: Scientific-Technical Analysis. Cambridge University Press.

IPCC, 1996c. Climate Change 1995: Economic and Social Dimensions of Climate Change. Cambridge University Press.

Janssen, M.A., Rotmans, J., 1995. Allocation of fossil $\mathrm{CO}_{2}$ emission rights quantifying cultural perspectives. Ecol. Econ. 13, 65-79.

Janssen, M.A., 1996. Meeting Targets: Tools to Support Integrated Assessment Modelling of Global Change. PhD Thesis ISBN 90-9009908-5, University of Maastricht, the Netherlands.

Johansson, T., Bodlund, B., Williams R. (Eds.), 1989. Electricity-efficient end-use and new generation technologies, and their planning implications. Lund University Press, Lund.

Kumar, K. 1987. Utopia and Anti-Utopia in Modern Times, Blackwell, Oxford.

Lempert, R.J., Schlesinger, M.E., Bankes, S.C., 1995. When we don't know the costs or the benefits: Adaptive Strategies for Abating Climate Change. Climatic Change, no. 33, pp. 235-274.

Lenssen, N., Flavin, C., 1996. Sustainable energy for tomorrow's world: the case for an optimistic view of the future. Energy Future 24 (9), 769-781. 
Lindzen, R.S., 1990. Some coolness about global warming. Bull. Amer. Met. Soc. 71, 288-299.

Lovins, A.B., Lovins, H.L., 1991. Least-Cost Climate Stabilization. Ann. Rev. Energy Environ. 16, 433-531.

Maier-Reimer, E., Hasselmann, K., 1987. Transport and storage of carbon dioxide in the ocean-An inorganic oceancirculation carbon cycle model. Climate Dynamics 2, 63-90.

Malthus, T., 1798. Essays on population.

Manne, A.S., Richels, R.G., 1992. Buying Greenhouse Insurance: The Economic Costs of $\mathrm{CO}_{2}$ Emission Limits. MIT Press, Cambridge, MA.

Manne, A.S., Mendelsohn, R., Richels, R.G., 1994. MERGE: A model for evaluating regional and global effects of GHG reduction policies. In: Nakicenovic, N., Nordhaus, W.D., Richels, R., Toth, F.L. (Eds.), Integrative Assessment of Mitigation, Impacts, and Adaptation to Climate Change. 143-172, CP-94-0, IIASA, Laxenburg, Austria.

More, T., 1516. Utopia. Cassel, London (1898).

Meadows, D.H., Meadows, D.L., Randers, J., Behrens, W.W., 1972. The Limits to Growth. Universe Books, New York.

Meadows, D.H., Meadows, D.L., Randers, J., 1991. Beyond the Limits. Earthscan Publications, London.

Nordhaus, W.D., 1991. A survey of the costs of reduction of greenhouse gases. Energy J. 12 (1), 37-65.

Nordhaus, W.D., 1994. Managing the Global Commons: The Economics of Climate Change. MIT Press, Cambridge, MA.

Peck, S.C., Teisberg, T.J., 1992. CETA: A Model for Carbon Emission Trajectory Assessment. The Energy J., Vol. 13, No. 1.

Proops, J.L.R., 1989. Ecological economics: rationale and problem areas. Ecol. Econ. 1, 59-76.
Rayner, S., 1991. A cultural perspective on the structure and implementation of global environmental agreements. Eval. rev. 15 (1), 75-102.

Rotmans, J., de Vries, H.J.M. (Eds.), 1997. Perspectives on global futures: The TARGETS approach, Cambridge University Press, Cambridge, UK.

Schmidheiney, S. et al. 1992. Changing course: a global business perspective on development and the environment, MIT Press, Cambridge, MA, USA.

Schwartz, M., Thompson, M., 1990. Divided We Stand: Redefining Politics, Technology, and Social Choice. Harvester Wheatsheaf, New York.

Simon, J.L., 1980. Resources, population, environment: an oversupply of false bad news. Science 208, 1431-1437.

Thompson, M., Taylor, P., 1986. The Surprise Game: An Exploration of Constrained Relativism. Warwick Papers in Management, no. 1, Institute for Management Research and Development, University of Warwick: Coventry.

Thompson, M., Ellis, R., Wildawsky, A., 1990. Cultural Theory. Westview Press, Boulder, CO.

Thompson, M., 1996. Cultural Theory and Integrated Assessment, submitted to Environmental Modeling and Assessment.

Trisoglio, A., Swart, R., Thompson, M., Rotmans, J., Dowlatabadi, H., Rahman, A., De Vries, B., 1994. Scenarios of climate change: making the human factor explicit. Battelle Pacific Northwest Laboratories, Washington.

Van Asselt, M.B.A., Rotmans, J., 1996. Uncertainty in perspective: a cultural perspective based approach. Global Environmental Change, 6(2), 121-158.

Waldrop, M., 1992. Complexity: The Emerging Science at the Edge of Order and Chaos. Simon and Schuster. 